\title{
Diastolic disorder inherent to doxorubicin cardiotoxicity
}

\author{
${ }^{\star}$ Lilia Tacu, Valeriu Cobet \\ Department of Pathophysiology and Clinical Pathophysiology \\ Nicolae Testemitanu State University of Medicine and Pharmacy, Chisinau, the Republic of Moldova \\ Authors' ORCID iDs, academic degrees and contributions are available at the end of the article \\ ${ }^{*}$ Corresponding author - Lilia Tacu, e-mail: lilia.tacu@usmf.md \\ Manuscript received July 27, 2021; revised manuscript October 05, 2021; published online October 12, 2021
}

\begin{abstract}
Background: The doxorubicin (Dx) cardiotoxicity is manifested by a marked heart failure evolution. The impact of Dx on lusitrop functions of the heart and the inherent diastolic disorders have a theoretical and practical value for the connection cardiology-oncology.

Material and methods: Dx cardiotoxicity was reproduced by its administration i/p in white rats in cumulative dose $16 \mathrm{mg} / \mathrm{kg}$ (Dx group n=9). Control group $(\mathrm{n}=9)$ received only physiological solution. The study was performed in vitro by using models of isolated heart perfusion in either isovolumic or exterior working regimens. The assayed indices of diastole functioning were: left ventricle (LV) end-diastolic pressure (LVEDP), diastolic stiffness, isovolumic relaxation velocity (-dP/dTmax) and protodiastolic pressure of LV (LVPDP).

Results: The indices of diastolic disorders induced by Dx were elevation of LVEDP, diastolic stiffness and LVPDP in a range of 97-168\% comparing to control as well as diminution of -dP/dTmax in the physiological pattern of hemodynamics. LVEDP increased more in conditions of calcium overloading or endothelin-1 (ET-1) action that are involved in pathogenesis of diastolic rigidity. Dx action led to decrease of myocardium resistance to ischemiareperfusion action resulting in the LVEDP elevation by $53 \%$ comparing to control.

Conclusions: 1. Diastolic disorders inherent to Dx cardiotoxicity are manifested by the increase of LVEDP and diastolic stiffness. 2. Diastolic disorders compromised the volume-pressure relationship of LV, the adaptation of the heart to effort with volume, being more pronounced during the action of calcium excess and ET- 1 .
\end{abstract}

Key words: doxorubicin cardiotoxicity, diastolic relaxation disorders.

Cite this article

Tacu L., Cobet V. Diastolic disorder inherent to doxorubicin cardiotoxicity. Mold Med J. 2021;64(4):23-28. https://doi.org/10.52418/moldovanmed-j.64-4.21.04.

\section{Introduction}

The diastolic relaxation of the heart is an important phase of cardiac activity, which assures, by adequate fulfil of left ventricle cavity (LV), the feasibility of Frank Starling mechanism realizing (the length - force law) and of pumping function. But, on the other hand, the diastole is a vulnerable cardiac phase to the cardiovascular risk factors, but diastolic disorders are imposed as an early predictor of heart failure $[1,2]$. Conceptually, the cardiac lusitrope function is dependent on different factors and conditions, like turnover of calcium into cardiomyocyte, indispensable for working of ionic pumps (first of all SERCA2a), as well as structural changes which develop at extracellular matrix and cardiac myocytes level $[3,4]$.

Among natural and synthetic factors with cardiotoxic action, the anthracyclines (election drugs in neoplasm treatment, e. g. doxorubicin) are positioned in a special format in the interdisciplinary plan of collaboration and mutual interest, oncology-cardiology. Cardiotoxicity of doxorubicin (Dx) may already progress to cumulative sub-therapeutic doses of the drug $(<500 \mathrm{mg} / \mathrm{m} 2)$, manifested by the onset and rapid progression of heart failure inherent to dilated cardiomyopathy with a marked risk of mortality indifferent of patient age.
Thus, there is a need to stop the administration of the drug, which reduces the chances of survival of the cancer patient, especially with leukemia and lymphoma. In this aspect, it is obvious that oncology and cardiology have a common task: the early detection of Dx cardiotoxicity and application of measures to limit the characteristic myocardial injuries and dysfunction.

The evaluation of Dx cardiotoxicity in terms of estimation the nature of diastolic disorders is authentic and important from several points of view. First of all it is needed to highlight the pathogenetic mechanisms of triggering and exacerbation of heart failure. Secondly, the demarcation of functional predictors of Dx cardiotoxicity is important. And thirdly, it is important to determine the targets of pathogenetic treatment of heart failure.

The aim of the study was to evaluate in vitro the disturbances of diastolic relaxation characteristic for Dx cardiotoxicity.

\section{Material and methods}

Myocardial Dx disorder was reproduced in white rats by $\mathrm{i} / \mathrm{p}$ administration of Dx (cumulative dose $16 \mathrm{mg} / \mathrm{kg}$ in 2 weeks, 2 injections/per week at a dose of $4.0 \mathrm{mg} / \mathrm{kg}$ ). The animals were sacrificed by euthanasia (sodium thiopental, 
$0.4 \mathrm{mg} / \mathrm{kg}$ ) 10 days after the last anthracycline injection, as doxorubicin is a drug that, based on reduced clearance, accumulates in the body. This model of Dx-induced cardiotoxicity has been used by other authors, aiming to highlight the link between the action of anthracycline and the inflammatory response of the myocardium [5].

The isolated heart was perfused in isovolumic or working regime respectively according to the Langendorff and Neely-Rovetto method, the functional indices of LV being estimated by technical device for recording real-time parameters „Bio-Shel” (Australia) or the autograph Linearcorder MARK WR3101 (Germany) connected to the mechanical sensor. For estimation of diastolic relaxation peculiarities together with the performance of the LV pump function, were used the following functional indices:

- End-diastolic pressure (LVEDP),

- Protodiastolic pressure (LVPDP),

- Maximum isovolumic relaxation rate (-dP/dTmax),

- Diastolic stiffness,

- Aortic jet velocity,

- Coronary flow,

- Cardiac output.

Functional reserves of diastole were estimated in various exercise stress tests:

- Modification of filling pressure of the left atrium (effort with volume),

- Increasing the filling volume of the LV cavity (volume-pressure relationship),

- Increasing the retrograde perfusion pressure (coronary pressure - diastolic compliance relationship),

- Stimulation of isolated heart with calcium and Endothelin 1 (ET-1),

- The ischemia-reperfusion impact.

The obtained data, exposed by the value $\mathrm{M} \pm \mathrm{m}$ (mean and standard error), were compared and statistically analyzed, according to the t-Student criteria, with the control group (intact animals) or with indices attested before the exercise stress test. The error margin less than $5 \%$ was considered admissible and the deviation from the reference value was significant $(\mathrm{p}<0.05)$.

\section{Results}

Dx cardiotoxicity was imposed by marked impairment of diastolic relaxation, that already has been attested in the optimal perfusion regime of the isolated heart, when the filling pressure of the left atrium (LAFP) was $15 \mathrm{cmH}_{2} \mathrm{O}$, and the pressure in the aorta $-80 \mathrm{cmH}_{2} \mathrm{O}$ (tab. 1).

One of the main important indices, estimating the feasibility of diastolic relaxation, PTDVS, was increased by $168 \%$ in the group with Dx compared to the control one, which was associated with increased of more than $109 \%$ the value of diastolic stiffness. The diastolic disorder is based on disturbance of relaxation isovolumic phase of the heart, as key parameter of it, -dP/dT max, demonstrates a significant decline of $24.81 \%$. Impaired diastolic relaxation compromises systolic contraction due to the inefficiency of the Frank-Starling mechanism. Thus, the protodiastolic pressure, which means
LV pressure at the end of systole, is elevated by $97 \%$ in the group with Dx.

Table 1. Indices of diastolic relaxation of the isolated heart perfused in physiological regime

\begin{tabular}{|c|c|c|c|}
\hline \multirow{2}{*}{ Indices } & \multicolumn{2}{|c|}{ Group } & \multirow{2}{*}{$p$} \\
\hline & Control $(n=9)$ & $D x(n=9)$ & \\
\hline $\begin{array}{l}\text { End-diastolic } \\
\text { pressure (LVEDP) }\end{array}$ & $4.7 \pm 0.26$ & $\begin{array}{c}12.6 \pm 0.78 \\
+168 \% \text { vs control }\end{array}$ & $<0.001$ \\
\hline $\begin{array}{l}-\mathrm{dP} / \mathrm{dT} \text { max, mm } \\
\mathrm{Hg} / \mathrm{sec}\end{array}$ & $6710 \pm 174$ & $\begin{array}{c}5045 \pm 120 \\
-24.81 \% \text { vs control }\end{array}$ & $<0.05$ \\
\hline $\begin{array}{l}\text { Diastolic stiffness of } \\
\mathrm{LV}, \mathrm{mm} \mathrm{Hg} / \mathrm{ml}\end{array}$ & $29.8 \pm 1.7$ & $\begin{array}{c}62.5 \pm 4.4+109.73 \% \\
\text { vs control }\end{array}$ & $<0.01$ \\
\hline $\begin{array}{l}\text { Protodiastolic pres- } \\
\text { sure of } \mathrm{LV}, \mathrm{mm} \mathrm{Hg}\end{array}$ & $0.78 \pm 0.06$ & $\begin{array}{c}1.53 \pm 0.08 \\
+97 \% \text { vs control }\end{array}$ & $<0.01$ \\
\hline
\end{tabular}

The manifestations of the heart lusitrop function disturbances at administration of Dx can be determined by estimating the diastolic stiffness of the LV, which was clearly increased by $109 \%$ compared to the control index. Diastolic stiffness shows the ratio between rate of increasing LV pressure during diastolic filling to the stroke volume or systolic volume. As a consequence, the parameters of the LV pump function were significantly reduced compared to the control group (tab. 2).

The aortic jet decreased by $40.47 \%$, which determined the decreased cardiac output by $36.9 \%$, caused by decreased coronary flow by $31.65 \%$.

Manifestations of impaired diastolic relaxation in the group with Dx become more pronounced in the hemodynamic effort tests, with calcium, ET-1, as well as in the impact of ischemia-reperfusion.

Table 2. The values of indices of the isolated heart pump function

\begin{tabular}{|l|c|c|c|}
\hline \multirow{2}{*}{ Indices } & \multicolumn{2}{|c|}{ Group } & \multirow{2}{*}{$\mathbf{p}$} \\
\cline { 2 - 3 } & Control $(\mathbf{n}=\mathbf{9})$ & $\mathbf{D x}(\mathbf{n}=9)$ & \\
\hline $\begin{array}{l}\text { Aortic jet velocity, } \\
\mathrm{ml} / \mathrm{min}\end{array}$ & $21.5 \pm 1.4$ & $\begin{array}{c}12.8 \pm 0.8 \\
-40.47 \% \text { vs control }\end{array}$ & \\
\hline $\begin{array}{l}\text { Coronary flow, } \\
\mathrm{ml} / \mathrm{min}\end{array}$ & $15.9 \pm 1.2$ & $\begin{array}{c}10.8 \pm 1.2 \\
-31.65 \% \text { vs control }\end{array}$ & $<0.01$ \\
\hline $\begin{array}{l}\text { Cardiac output, } \\
\mathrm{ml} / \mathrm{min}\end{array}$ & $37.4 \pm 1.9$ & $\begin{array}{c}23.6 \pm 1.3 \\
-36.9 \% \text { vs control }\end{array}$ & $<0.01$ \\
\hline
\end{tabular}

In the exercise effort test with minimal filling pressure of the left atrium (LAFP) $\left(5 \mathrm{~cm} \mathrm{H}_{2} \mathrm{O}\right)$ the depreciation of the index $-\mathrm{dP} / \mathrm{dT}$ max compared to the control prototype increased from $24.81 \%$ to $32.77 \%$ (tab. 3 ).

Compared to the index attested in the perfusion of the isolated heart in physiological comfort regime, its value increased in both groups, but the enhancement was different: in the control group - $\mathrm{dP} / \mathrm{dT}$ max was increased by $19 \%$ and in the group with $\mathrm{Dx}$ - only by $7 \%$. In conditions of decreasing the venous return to the heart, the phase of isovolumic relaxation of the heart has a decisive significance in order to ensure as much as possible the filling of the left ventricular cavity based on developing the adequate pressure gradient. 
Table 3. Value of functional indices of the cord isolated at the minimum level of LAFP

\begin{tabular}{|l|c|c|c|}
\hline \multirow{2}{*}{ Indices } & \multicolumn{2}{|c|}{ Group } & \multirow{2}{*}{$\mathbf{p}$} \\
\cline { 2 - 3 } & $\begin{array}{c}\text { Control } \\
(\mathbf{n}=9)\end{array}$ & $\mathbf{D x}(\mathbf{n}=9)$ & \\
\hline Aortic jet velocity, $\mathrm{ml} / \mathrm{min}$ & $5.7 \pm 0.3$ & $\begin{array}{c}1.6 \pm 0.1 \\
-71.93 \% \text { vs control }\end{array}$ & $<0.001$ \\
\hline $\begin{array}{l}\text { End-diastolic pressure of } \\
\text { LV, } \mathrm{mm} \mathrm{Hg}\end{array}$ & $2.2 \pm 0.15$ & $\begin{array}{c}3.9 \pm 0.19 \\
+78 \% \text { vs control }\end{array}$ & $<0.001$ \\
\hline $\begin{array}{l}\text { Protodiastolic pressure of } \\
\text { LV, mm Hg }\end{array}$ & $0.22 \pm 0.02$ & $\begin{array}{c}0.48 \pm 0.04 \\
+119 \% \text { vs control }\end{array}$ & $<0.01$ \\
\hline -dP/dT max, $\mathrm{mm} \mathrm{Hg} / \mathrm{sec}$ & $7966 \pm 188$ & $\begin{array}{c}5356 \pm 149 \\
-32.77 \% \text { vs control }\end{array}$ & $<0.05$ \\
\hline
\end{tabular}

The pumping function of LV appreciated after the aortic jet had a decline of $87.5 \%$ (in the control group - 73.5\%) reaching an average value of $1.6 \mathrm{ml} / \mathrm{min}$ that is $71.93 \%$ lower than control index $(5.7 \pm 0.3 \mathrm{ml} / \mathrm{min})$. The end-diastolic pressure decreased intelligibly in both groups, but its value remaining significantly higher in the group with $\mathrm{Dx}$, the difference being $78 \%$. The protodiastolic pressure decreased simultaneously with the decreasing of filling pressure of the left atrium, the smaller rebound being characteristic for Dx cardiotoxicity (68.83 vs $71.8 \%$ ), which indicates a weaker systole compared to the control group.

In the sample with maximum LAFP $(25 \mathrm{cmH} 2 \mathrm{O})$ the LV filling is facilitated due to an artificial gradient installed between the left atrium and the left ventricle. However, the reduced diastolic compliance of the myocardium in the group with Dx conditioned a higher elevation of LVEDP compared to the control pattern: $5.6 \mathrm{vs} 2.1 \mathrm{~mm} \mathrm{Hg}$ (tab. 4).

As a consequence, the value of LVEDP in this volume stress test became $184 \%$ higher than the index in the control group.

The reduced diastolic compliance was manifested by increasing the value of diastolic stiffness by $129 \%$, this being higher than the enhancement attested to the perfusion of isolated heart in physiological regime (109.73\%). Limiting the filling of the LV cavity due to increased diastolic stiffness of the myocardium led to lower values of the pump function indices. The aortic jet, for example, was found to be reduced by $42.6 \%$, and stroke volume - by $25 \%$.

Table 4. Values of functional indices of the heart isolated at the maximum level of LAFP

\begin{tabular}{|c|c|c|c|}
\hline \multirow{2}{*}{ Indices } & \multicolumn{2}{|c|}{ Groups } & \multirow{2}{*}{$p$} \\
\hline & Control $(n=9)$ & $D x(n=9)$ & \\
\hline $\begin{array}{l}\text { Aortic jet velocity, } \\
\mathrm{ml} / \mathrm{min}\end{array}$ & $31.7 \pm 2.5$ & $\begin{array}{c}18.2 \pm 1.4 \\
-42.6 \% \text { vs control }\end{array}$ & $<0.001$ \\
\hline Stroke volume, $\mathrm{ml}$ & $0.2 \pm 0.009$ & $\begin{array}{c}0.15 \pm 0.009 \\
-25 \% \text { vs control }\end{array}$ & $<0.01$ \\
\hline $\begin{array}{l}\text { End-diastolic pres- } \\
\text { sure of } \mathrm{LV}, \mathrm{mm} \mathrm{Hg}\end{array}$ & $6.8 \pm 0.52$ & $\begin{array}{c}19.3 \pm 1.83 \\
+184 \% \text { vs control } \\
\end{array}$ & $<0.001$ \\
\hline $\begin{array}{l}\text { Diastolic stiffness, } \\
\mathrm{mm} \mathrm{Hg} / \mathrm{ml}\end{array}$ & $31.86 \pm 1.8$ & $\begin{array}{c}72.95 \pm 4.5 \\
+129 \% \text { vs control } \\
\end{array}$ & $<0.001$ \\
\hline $\begin{array}{l}-\mathrm{dP} / \mathrm{dT} \text { max, mm } \\
\mathrm{Hg} / \mathrm{sec}\end{array}$ & $7718 \pm 156$ & $\begin{array}{c}5296 \pm 141 \\
-31.39 \% \text { vs control }\end{array}$ & $<0.05$ \\
\hline
\end{tabular}

Evidence of impaired diastolic relaxation at Dx administration was also confirmed on the retrograde perfusion model without recirculation of the isolated heart (Langedorff method, to unify the initial values of LVEDP) in the conditions of increased filling (tab. 5).

The impact of the gradual increasing of LV filling volume on LVEDP hemodynamics is different between batches, taking into account that initial volume was similar $(0.2 \mathrm{ml})$ and LVEDP was calibrated at $14 \mathrm{~mm} \mathrm{Hg}$ level. In the control group, the elevation of LVEDP, in conditions of increasing $\mathrm{LV}$ volume from 0.2 up to $0.4 \mathrm{ml}$, was found in a range of $7-51 \%$. The cardiotoxicity of doxorubicin increased the LVEDP to $95.8 \%$, which led to a significant $30 \%$ lag of the index at the end of the test: $27.4 \pm 1.6$ vs $21.2 \pm 1.2 \mathrm{~mm} \mathrm{Hg}$.

Due to a higher elevation of the end-diastolic pressure of LV in the group with $\mathrm{Dx}$, a more conclusive depreciation of coronary flow was attested. Compared to the control prototype, the decline of coronary flow in conditions of doubling the filling volume of LV was with $46 \%$ higher ( 45.33 vs $31.21 \%)$, and the final rebound of absolute value of the CF (coronary flow) was $21.65 \%(7.6 \pm 0.5 \mathrm{vs} 9.7 \pm 0.3 \mathrm{ml} / \mathrm{min})$.

Table 5. The hemodynamics of end-diastolic pressure and coronary flow in condition of gradual increasing of left ventricular filling volume

\begin{tabular}{|c|c|c|c|c|c|c|}
\hline \multirow{2}{*}{ Indices } & \multirow{2}{*}{ Groups } & \multirow{2}{*}{$\begin{array}{c}\text { Initial } \\
\text { LVFV }=0.20 \mathrm{ml}\end{array}$} & \multicolumn{4}{|c|}{ Left ventricular filling volume of isovolumic heart } \\
\hline & & & $0.25 \mathrm{ml}$ & $0.30 \mathrm{ml}$ & $0.35 \mathrm{ml}$ & $0.40 \mathrm{ml}$ \\
\hline \multirow[t]{2}{*}{ LVEDP mm Hg } & Control, $n=9$ & $14.0 \pm 0.3$ & $\begin{array}{c}15.1 \pm 0.7 \\
+7 \% \\
\end{array}$ & $\begin{array}{c}16.4 \pm 0.9 * \\
+17 \% \\
\end{array}$ & $\begin{array}{c}17.8 \pm 1.1 * \\
+27 \%\end{array}$ & $\begin{array}{c}21.2 \pm 1.2 * * \\
+51 \%\end{array}$ \\
\hline & $\begin{array}{l}D x \\
n=8\end{array}$ & $14.0 \pm 0.3$ & $\begin{array}{c}15.7 \pm 0.7 \\
+12 \%\end{array}$ & $\begin{array}{c}17.2 \pm 1.1 * \\
+22 \%\end{array}$ & $\begin{array}{c}20.5 \pm 1.3 * \\
+46 \%\end{array}$ & $\begin{array}{c}27.4 \pm 1.6 * * \\
+95.8 \% \\
p<0.05\end{array}$ \\
\hline \multirow[t]{2}{*}{$\mathrm{CF}, \mathrm{ml} / \mathrm{min}$} & Control, $n=9$ & $14.1 \pm 0.4$ & $\begin{array}{c}13.7 \pm 0.4 \\
-3 \% \\
\end{array}$ & $\begin{array}{c}12.4 \pm 0.3 * \\
-13 \% \\
\end{array}$ & $\begin{array}{c}11.0 \pm 0.4 * * \\
-22 \%\end{array}$ & $\begin{array}{c}9.7 \pm 0.3^{* *} \\
-31.21 \% \\
\end{array}$ \\
\hline & $\begin{array}{l}\mathrm{Dx} \\
\mathrm{n}=8\end{array}$ & $13.9 \pm 0.5$ & $\begin{array}{c}13.1 \pm 0.4 \\
-6 \%\end{array}$ & $\begin{array}{c}11.2 \pm 0.3 * \\
-20 \%\end{array}$ & $\begin{array}{c}9.3 \pm 0.4 \\
-34 \% \\
p<0.05\end{array}$ & $\begin{array}{c}7.6 \pm 0.5 * * \\
-45.33 \% \\
p<0.05\end{array}$ \\
\hline
\end{tabular}

Note: LVFV - left ventricular filling volume; CF - coronary flow; +/-\% - relative deviations of the indices compared to their initial value; $\mathrm{p}$ - the significance of the discrepancy versus the respective index; ${ }^{*}-\mathrm{p}<0.05$ versus initial value;

** $-\mathrm{p}<0.01$ versus initial value. 
An important intrinsic factor that influences the functionality of diastolic relaxation is the pressure of the coronary perfusion, which on the retrograde perfusion model of the isolated isovolumic heart is dependent on the perfusion volume of the coronary system. In this context, there was estimated the hemodynamics of LVEDP modification in conditions of increasing the pressure in the aortic estuary from 80 up to $120 \mathrm{cmH} 2 \mathrm{O}$ (tab. 6).

Table 6. The LVEDP hemodynamics in conditions of increased coronary pressure of the isolated isovolumic heart

\begin{tabular}{|l|c|c|c|}
\hline \multirow{2}{*}{ Groups } & \multicolumn{3}{|c|}{$\begin{array}{c}\text { Coronary perfusion pressure of the isolated } \\
\text { isovolumic heart }\left(\mathrm{cmH}_{2} \mathrm{O}\right)\end{array}$} \\
\cline { 2 - 4 } & $\mathbf{8 0}$ & 100 & 120 \\
\hline $\begin{array}{l}\text { Control } \\
(\mathrm{n}=9)\end{array}$ & $14 \mathrm{~mm} \mathrm{Hg}$ & $15.6 \pm 1.2$ & $16.3 \pm 1.4$ \\
\hline $\mathrm{Dx}(\mathrm{n}=9)$ & $14 \mathrm{~mm} \mathrm{Hg}$ & $\begin{array}{c}18.3 \pm 1.3 \\
+18 \% \text { vs control }\end{array}$ & $\begin{array}{c}19.8 \pm 1.5 \\
+22 \% \text { vs control }\end{array}$ \\
\hline $\mathrm{p}$ & & $<0.05$ & $<0.05$ \\
\hline
\end{tabular}

It should be mentioned that LVEDP was measured at the level of the initial or basal aortic pressure $(80 \mathrm{cmH} 2 \mathrm{O})$ equal in both batches with $14 \mathrm{mmHg}$, by the latex balloon placed in the cavity of the left ventricle. The progression of coronary hypertension has led in both groups to a natural effect - the elevation of LVEDP. But, in the group with Dx, the increase of the end-diastolic pressure of LV was much more pronounced. At the level of aortic pressure of $100 \mathrm{cmH} 2 \mathrm{O}$, the LVEDP value increased by $31 \%$ compared to the control increment of $12 \%$. At the maximum level of coronary pressure $(120 \mathrm{cmH} 2 \mathrm{O})$ the enhancement of LVEDP was $42 \%$, which is $147 \%$ higher than the control increment equal to $17 \%$. As a consequence at both levels of coronary blood pressure LVEDP in doxorubicin disorder of the heart was significantly higher compared to the control pattern by $18 \%$ and $22 \%$, respectively.

The lusitrop function of the heart is influenced by several neuroendocrine factors (e.g., ET-1, catecholamines, angiotensin II), which normally had a positive inotropic effect due to the increased calcium concentration in the sarcoplasm. In order to estimate the character of the diastole change under the action of ET- 1 and excess calcium, was appreciated the basal value, as well as the value of LVEDP, as well as the index value at the peak of stimulation of the isolated heart perfused in working regime (tab. 7).
Table 7. Modification of LVEDP to the action of ET-1 and excess of calcium

\begin{tabular}{|c|c|c|c|c|}
\hline \multirow[t]{2}{*}{ Groups } & \multicolumn{2}{|c|}{ ET-1 $\left(10^{-7} M\right)$} & \multicolumn{2}{|c|}{ Calcium (3.0 mM) } \\
\hline & Initial & Peak & Initial & Peak \\
\hline $\begin{array}{l}\text { Control } \\
(n=9)\end{array}$ & $4.9 \pm 0.29$ & $\begin{array}{c}6.1 \pm 0.55 \\
+25 \% \text { vs initial }\end{array}$ & $4.8 \pm 0.29$ & $\begin{array}{c}6.9 \pm 0.61 \\
+44 \% \text { vs initial }\end{array}$ \\
\hline$D x(n=9)$ & $12.5 \pm 0.87$ & $\begin{array}{c}17.7 \pm 1.26 \\
+42 \% \text { vs initial }\end{array}$ & $12.4 \pm 0.87$ & $\begin{array}{c}21.2 \pm 1.87 \\
+71 \% \text { vs initial }\end{array}$ \\
\hline $\begin{array}{l}\mathrm{p} \\
\text { (vs control) }\end{array}$ & $<0.001$ & $<0.001$ & $<0.001$ & $<0.001$ \\
\hline
\end{tabular}

The action of both factors on the isolated heart was imposed by elevating LVEDP, both in the control group and in the group with Dx, the more conclusive effect being characteristic for the excess of calcium. Remarkably, that enhancement of LVEDP was significantly higher in the doxorubicin group. Thus, under the action of ET- 1 the rate of LVEDP elevation was imposed by the ratio of 42 vs $25 \%$, and under the action of calcium excess (increasing the concentration of $\mathrm{Ca}^{2+}$ in perfusion from 2.5 up to $3.0 \mathrm{mM}$ ) -71 vs $44 \%$.

As a result of these quantitatively distinct changes, the cardiotoxicity of Dx was imposed by a clearly higher stimulation of LVEDP than the control, by 191\% under the action of ET-1 and by $208 \%$ under the action of calcium excess. These differences are obviously larger compared to the initially estimated patterns, so till stimulation of isolated heart.

A cardinal factor that detrimentally influences the diastolic functionality is myocardial ATP deficiency resulting in the progressive accumulation of calcium in the cardiomyocyte during diastole relaxation due to the incompetence of ionic pumps, primarily of the ATP-ase of sarcoplasmic reticulum (SERCA2a). This phenomenon affects the dissociation of actin-myosin complex and led to development of diastolic stiffness, which to a severe degree is noted as diastolic contracture. Because myocardial ischemia represents a major condition of impaired bioenergy synthesis and calcium metabolism, the severity of its impact on the LVEDP hemodynamics and capacity of lusitrope to restore function during reperfusion was estimated (tab. 8).

It should be mentioned that in both groups the basal value of LVEDP, until the action of ischemia, was installed at equal levels: $14 \pm 0.1 \mathrm{~mm} \mathrm{Hg}$. According to the estimated hemodynamics of LVEDP, cardiac doxorubicin disorder was manifested by a considerable reduction in myocardial tolerance to ischemic impact. Thus, LVEDP has increased during ischemia period of $30 \mathrm{~min}$ to the average value of $63.7 \mathrm{~mm}$

Table 8. The LVEDP hemodynamics during ischemia and isovolumic isolated heart reperfusion

\begin{tabular}{|c|c|c|c|c|c|c|c|c|}
\hline \multirow{2}{*}{ Groups } & \multicolumn{4}{|c|}{ Ischemia (min) } & \multicolumn{4}{|c|}{ Reperfusion (min) } \\
\hline & 5 & 10 & 20 & 30 & 5 & 10 & 30 & 45 \\
\hline Control (n=9) & $16.3 \pm 0.8$ & $27.2 \pm 1.7$ & $36.2 \pm 1.9$ & $41.7 \pm 2.3$ & $36.3 \pm 2.5$ & $27.9 \pm 2.3$ & $20.7 \pm 1.8$ & $14.9 \pm 1.1$ \\
\hline$D x(n=9)$ & $21.5 \pm 1.4$ & $38.8 \pm 2.1$ & $55.6 \pm 3.6$ & $63.7 \pm 4.4$ & $58.2 \pm 4.3$ & $46.5 \pm 3.3$ & $30.6 \pm 2.5$ & $22.8 \pm 1.4$ \\
\hline$p$ & $<0.05$ & $<0.05$ & $<0.01$ & $<0.01$ & $<0.05$ & $<0.05$ & $<0.05$ & $<0.01$ \\
\hline
\end{tabular}


$\mathrm{Hg}$, and in the control group the index reached $41.7 \pm 2.3$ $\mathrm{mm} \mathrm{Hg}$, the final difference being 53\%. Moreover, the quality of LVEDP recovery in the Dx group was much poorer. If in the control group the index at 45 minutes of reperfusion practically reached the basal level $(14.9 \pm 1.1 \mathrm{~mm} \mathrm{Hg})$, then in the group with Dx it remains clearly higher $(22.8 \pm 1.4 \mathrm{~mm}$ $\mathrm{Hg}$ ), the difference remaining at the levels of the final period of ischemia, $53 \%$.

\section{Discussion}

The researchers in vitro on isovolumic isolated and working heart perfusion models (Langedorff and Neely-Rovetto methods) have demonstrated that the cardiotoxicity of doxorubicin is imposed by significantly affecting diastolic relaxation. Already in physiological hemodynamic regime, LVEDP values and diastolic stiffness were considerably increased more than double (109-168\%) compared to the control group indices. Increased diastolic stiffness was associated with a significant $24.8 \%$ reduction in isovolumic relaxation rate (-dP/dTmax).

The diastolic disorder in the Dx group is one of the main causes of impaired pump function of the left ventricle, manifested by a $36.9 \%$ decline in cardiac output, as worsening lusitrop function indices in volume effort tests were accompanied by increased rebound of the pump function parameters. In conditions of reducing the venous return to the heart to the minimal value $(5 \mathrm{cmH} 2 \mathrm{O})$ the difference of the $-\mathrm{dP} /$ $\mathrm{dTmax}$ index compared to the control increased by $32 \%$, and the aortic jet rebound increased by $78 \%$. At maximum LV filling the increased diastolic stiffness of the myocardium led to elevation of LVEDP by about 2.3 times compared to the control, and the hemodynamics of the volume-pressure relationship gradually reproduced on the isovolumic isolated heart perfusion model has the pattern of an upward curve compared to the control prototype. The increased diastolic stiffness is conceptually viewed as an intrinsic factor of increasing myocardial mechanical stress that limits coronary perfusion especially in the subendocardial layer $[6,7]$.

In this study, the doubling of the filling volume of the isolated isovolumic heart was manifested in the Dx disorder of the myocardium by decreasing the coronary flow more accentuated compared to the control pattern by $46 \%$, which correlated with an end-diastolic pressure of LV well above the control level. Impairment of coronary perfusion is an important pathogenetic factor in the disorder of the heart's adaptation to overload with volume and resistance, especially when myocardial dysfunction is directly related to impaired endothelium-dependent vascular relaxation, which can be compensated by the feasibility of the Vanhoutte phenomenon based on repolarization mechanism of vascular muscle media [8].

It should be mentioned that in the interface of dependence the coronary perfusion on the diastolic myocardial rigidity, it is also valid the inverse relation: the coronary flow influences the diastolic relaxation. In the presented research this aspect was confirmed. Thus, the increase of the retrograde perfusion pressure of the isolated isovolumic heart by $50 \%$ led to the elevation of LVEDP, while in the group with
Dx the index increase was $147 \%$ higher compared to the control increase.

One of the mechanisms highlighted in this study on the impairment of diastolic relaxation in the repeated administration of Dx is the incompetence of the control system of calcium ion turnover in the cardiomyocyte during the systole-diastole cycle. The increasing calcium concentration in perfusion by $0.5 \mathrm{mM}$ led to a more conclusive elevation of the LVEDP value by $62 \%$ compared to the rate of increase of the control index, which indicates the dysfunction of the calcium pumps, first of all the ATP-ases of the sarcoplasmic reticulum (SERCA2a) together with myocardial energy deficit. A similar phenomenon was observed in the isolated heart stimulation with ET-1, which increases the influx of calcium following the activation of ETA receptors. The diastolic disorder at the peak of stimulation of the isolated heart perfused in working regime with ET-1 was imposed by negative inotropic effect, manifested by decreased LV systolic pressure and cardiac output, evidences associated with a more pronounced elevation of LVEDP [9].

The role of excess calcium in diastolic disorder under the cardiotoxic impact of Dx was confirmed in a previous study, in which the chronic or acute action of taurine (natural modulator of calcium metabolism and bioenergetics) significantly improved the lusitrop function of the heart as well as parameters of LV pump function [10]. The similar results were obtained by other authors, who demonstrated the benefit of taurine administered for 14 days in the model of Dx myocardial disorder in rats on echocardiographic indicators, the first on the reduction of LV end-diastolic volume as a true sign of diastole improvement [11]. Taurine also has a remarkable antioxidant effect, and Dx cardiotoxicity, on the contrary, is marked by a prooxidant effect and, respectively, the activation of oxidative stress [12].

The diastolic disorder in the group with Dx was characterized by a more pronounced ischemic contracture vs control. Moreover, during the reperfusion period, the restoration of the lusitrop function of the heart in the group with Dx was frankly compromised, so that LVEDP remains 53\% above the control index. The pathophysiological substrate of the ischemia-reperfusion impact is determined by the rapid energetic decline, the accumulation of calcium in the heart cells, as well as the excess of oxygen free radicals. These pathogenetic mechanisms are the main elements of the pathophysiological interface regarding the disturbance of diastolic relaxation and the evolution of doxorubicin heart failure.

The impairment of diastole under the cardiotoxic action of Dx may also be related to the detrimental action of anthracycline on the extracellular matrix. In the context of the latest literature data is to be highlighted the effect of Dx to induce heart cell death by apoptosis, pyroptosis and ferroptosis [13].

Pyroptosis is triggered by the inflammatory response of the myocardium induced by $\mathrm{Dx}$, and the increased expression of proinflammatory cytokines and chemokines remains during the cessation of its action. The inflammatory responses together with oxygen free radicals influence the extracellular matrix by activating metalloproteinases, fibroblasts and 
interstitial macrophages. As a result, the extracellular matrix increases due to fibrillar collagen type I and III, as well as degraded collagen. These changes in the interstitium obviously decrease the diastolic compliance of the myocardium caused by reducing cardiomyocyte counts.

Ferroptosis under the action of Dx is mediated by the accumulation of iron ions in the mitochondria of the cardiomyocyte, which has a negative effect on the synthesis control of ATP molecules and oxygen free radicals, which justifies this phenomenon as a mechanism responsible for Dx cardiotoxicity [14], as well as a heart protection target in cancer patients exposed to the anthracyclines action [15].

An important aspect of the clinical applicability of the data obtained in cardiology-oncology is the proof of the key role of isovolumic diastolic relaxation disorder of the heart in disturbance of the LV pump function, and on the other hand elucidating the mechanism of early growth of the Tei index in cardiac patients exposed to cardiotoxic effect of anthracyclines [16]. Therefore, the increase of the Tei index values as an early predictor of cardiac dysfunction under the action of Dx is based primarily on increasing the time of isovolumic relaxation of the heart resulting in reduced ejection time of the left ventricle.

\section{Conclusions}

1. Impairment of diastolic relaxation inherent to Dx cardiotoxicity is manifested mainly by significant increase of LVEDP and diastolic stiffness in association with reducing the isovolumic diastolic relaxation velocity.

2. Diastolic disorders compromise the volume-pressure relationship of $\mathrm{LV}$, the adaptation of the heart to effort with volume and become more pronounced during the action of calcium excess and ET-1.

\section{References}

1. Nishimura RA, Borlaug BA. Diastology for the clinician. J Cardiol. 2019;73(6):445-452. doi: 10.1016/j.jjcc.2019.03.002.

2. Kim IC, Hong GR. Intraventricular flow: more than pretty pictures. Heart Fail Clin. 2019;15(2):257-265. doi: 10.1016/j.hfc.2018.12.005.

3. Gillebert TC, De Pauw M, Timmermans F. Echo-Doppler assessment of diastole: flow, function, and haemodynamics. Heart. 2013;99(1):55-64. doi: 10.1136/heartjnl-2012-301961.

4. Nagueh SF. Left ventricular diastolic function: understanding pathophysiology, diagnosis, and prognosis with echocardiography. J Am Coll Cardiovasc Imaging. 2020;13(1 Pt 2):228-244. doi: 10.1016/j. jcmg.2018.10.038.

5. Argun M, Uzum K, Sonmez M, et al. Cardioprotective effect of metformin against doxorubicin cardiotoxicity in rats. Anatol J Cardiol. 2016;16(4):234-241. doi: 10.5152/akd.2015.6185.

6. Popovici M, Cobeț V, Popovici I, et al. Perfuzia coronariană și stresul miocardic: relații reciproce [Coronary perfusion and myocardial stress: reciprocal relation]. Buletinul Academiei de Ştiințe a Moldovei. Ştiințe Medicale. 2008;4(18):23-32. Romanian.

7. Galderisi M, Cicala S, De Simone L, et al. Impact of myocardial diastolic dysfunction on coronary flow reserve in hypertensive patients with left ventricular hypertrophy. Ital Heart J. 2001;2(9):677-684.

8. Tacu L, Ivanov M, Cobet $\mathrm{V}$, et al. Vanhoutte and Bowditch phenomena in heart failure: the relation with ischemia-reperfusion impact. Eur J Heart Fail. 2018;20(Suppl 1):335.

9. Cobeț V. Reglarea tonusului coronarian prin hiperpolarizare: mecanism compensator în disfuncția endotelială [The regulation of coronary tonus by hyperpolarisation: compensatory mechanism in endothelial dysfunction]. Buletinul Academiei de Științe a Moldovei. Științe Medicale. 2010;2(25):65-72. Romanian.

10. Tacu L, Cobeț V. Efectele endotelinei 1 în afecțiunea doxorubicinică a cordului [The endothelin-1 effects in doxorubicin disorder of the heart]. Buletinul Academiei de Ştiințe a Moldovei. Științe Medicale. 2020;1(65):145-151. Romanian.

11. Cobet V, Tacu L, Hajawi O, et al. Taurine blunts the doxorubicin cardiotoxicity: chronic and acute effects. EP Europace. 2021;23(Suppl 3):iii585. https://doi.org/10.1093/europace/euab116.533.

12. Baris VO, Gedikl E, Yersal N, et al. Protective effect of taurine against doxorubicin-induced cardiotoxicity in rats: echocardiographical and histological findings. Amino Acids. 2019;51(10-12):1649-1655. doi: 10.1007/s00726-019-02801-7.

13. Wang $\mathrm{Y}$, Ren $\mathrm{K}, \mathrm{Lu} \mathrm{Q}$, et al. Inhibiting effects of taurine on doxorubicininduced oxidative stress in rats. Adv Mater Res. 2014;912-914:214-216. https://doi.org/10.4028/www.scientific.net/AMR.912-914.214.

14. Christidi E, Brunham LR. Regulated cell death pathways in doxorubicininduced cardiotoxicity. Cell Death Dis. 2021;12(4):339. https://doi. org/10.1038/s41419-021-03614-x.

15. Tadokoro T, Ikeda M, Ide T, et al. Mitochondria-dependent ferroptosis plays a pivotal role in doxorubicin cardiotoxicity. JCI Insight. 2020;5(9):e132747. doi: 10.1172/jci.insight.132747.

16. Fang X, Wang H, Han D, et al. Ferroptosis as a target for protection against cardiomyopathy. Proc Natl Acad Sci USA. 2019;116(7):26722680. doi: 10.1073/pnas.1821022116.

\section{Authors' ORCID iDs and academic degrees \\ Lilia Tacu, MD, PhD Applicant, Assistant Professor - https://orcid.org/0000-0003-0940-2527 \\ Valeriu Cobet, MD, PhD, Professor - https://orcid.org/0000-0002-6141-1108}

\section{Authors' contributions}

LT interpreted the data and performed the analytical part of the laboratory work, drafted the first manuscript; VC conceptualized the project, designed the research and revised the manuscript critically.

\section{Funding}

This study was supported by Nicolae Testemitanu State University of Medicine and Pharmacy. The trial was the authors' initiative. The authors are independent and take responsibility for the integrity of the data and accuracy of the data analysis.

\section{Ethics approval and consent to participate}

The research project was approved by the Research Ethics Committee of Nicolae Testemitanu State University of Medicine and Pharmacy (Protocol No 40, 05.12.2016).

\section{Conflict of Interests}

No competing interests were disclosed. 